Article

\title{
Properties Analysis and Preparation of Biochar-Graphene Composites Under a One-Step Dip Coating Method in Water Treatment
}

\author{
Ze Yu ${ }^{1,2}$, Wenxuan Wang ${ }^{1}$, He Gao ${ }^{1,2}$ and Daxin Liang ${ }^{1,2, *}$ \\ 1 College of Materials Science and Engineering, Northeast Forestry University, Harbin 150040, China; \\ yz19960216@nefu.edu.cn (Z.Y.); wxwang@nefu.edu.cn (W.W.); 784124957@nefu.edu.cn (H.G.) \\ 2 Key Laboratory of Bio-based Materials Science and Technology, Ministry of Education, Northeast Forestry \\ University, Harbin 150040, China \\ * Correspondence: daxin.liang@nefu.edu.cn
}

Received: 22 April 2020; Accepted: 22 May 2020; Published: 26 May 2020

\begin{abstract}
In order to improve the adsorption efficiency of biochar in water treatment, biochargraphene (BG) composites were prepared by the one-step dip coating method and applied to remove phthalates from water. Firstly, the materials and equipment needed for the experiment are introduced. The steps of preparing graphene oxide (GO) by the improved Hummers method and BG composites by one-step dip coating are discussed. Then, the morphology characterization, adsorption performance measurement, and isothermal model of BG composites are introduced. Finally, the structure characterization, adsorption kinetics, and adsorption isotherms of BG composites are analyzed. The results show that the properties of biochar could be changed by one-step dip coating, and the biochar could form composites with graphene. Compared with biochar, biochar-graphene composites have greater surface area and porosity. When the pyrolysis temperature was $600{ }^{\circ} \mathrm{C}$, the specific surface area of biochar was $8.4 \mathrm{~m}^{2} \mathrm{~g}^{-1}$, and the specific surface area of the biochar-graphene composite was $221.3 \mathrm{~m}^{2} \mathrm{~g}^{-1}$. When the temperature was $300^{\circ} \mathrm{C}$, the specific surface area of biochar was $11.01 \mathrm{~m}^{2} \mathrm{~g}^{-1}$, and the specific surface area of biochar-graphene composite was $251.82 \mathrm{~m}^{2} \mathrm{~g}^{-1}$. The formation of graphene on the surface of biochar can increase the stability of the composite and acts as a very high potential active site. The porous structure and surface properties of biochar-graphene composites regulate the adsorption rate of pollutant molecules, thereby improving the adsorption performance. When the adsorption equilibrium was reached, the adsorption effect of phthalate esters on the biochar/graphene composite at the pyrolysis temperature of $600{ }^{\circ} \mathrm{C}$ was the best, and the adsorption capacity of Dimethyl phthalate (DMP)was $35.2 \mathrm{mg} / \mathrm{g}$, that of Diethyl phthalate (DEP) was $26.4 \mathrm{mg} / \mathrm{g}$, and that of Dibutyl phthalate (DBP) was $25.1 \mathrm{mg} / \mathrm{g}$. The adsorption effect of DMP was the best. The results of the isotherm study indicate that the adsorption of phthalates by BG composites has great potential, which provides a good theoretical basis for the application of BG composites in environmental protection in China.
\end{abstract}

Keywords: water treatment; one step dip coating method; carbon-based materials-graphene composites; adsorption capacity; the isothermal model

\section{Introduction}

Since China's reform and opening up, China's economy has been developing rapidly, and its industrial structure has been constantly upgraded. With the rapid development, environmental pollution has become more and more serious. Environmental pollution has seriously restricted the sustainable development of China's economy and society. Water pollution is becoming more and more serious, so it is urgent to control water pollution [1-3]. 
Water pollution refers to the fact that the intervention of certain substances in water exceeds the self-purification capacity of water, resulting in the change of physical and chemical properties and biological properties of water and the destruction of the original ecosystem of water [4-7]. The problem of water pollution not only reduces the use value of water, but also causes harm to the human body. Moreover, it will destroy the ecological environment and lead to the deterioration of water quality [8]. At present, the common water pollution treatment methods are divided into physical methods and chemical methods. Common physical methods include coagulation and flocculation, adsorption, and ultrasonic methods, while chemical methods often include chemical precipitation, solvent extraction, and separation, as well as active sludge dyeing and oxidation methods [9]. Among them, the adsorption method is widely used in water pollution treatment because of its advantages of simple operation, economic efficiency, reusability of adsorbents, and no secondary pollution. The commonly used adsorbents are activated carbon, alumina, and molecular sieves, but the high price of adsorbents limits their application in real life. Therefore, it is an urgent problem to develop a cheap and efficient adsorbent. Carbon-based materials have been widely used in various fields due to their good mechanical, chemical, physical, and thermal properties, and are of great significance to improving people's quality of life [10]. Carbon-based materials refer to carbon-rich nanostructures such as biochar, carbon nanotubes, graphene, Graphene oxide (GO), fullerene, carbon nano fiber $(\mathrm{CNF})$, and carbon nanofibers [11]. Among them, biochar is a carbon-rich solid obtained from the pyrolysis of biochar at high temperature in the atmosphere of limited oxygen or no oxygen. It has the characteristics of abundant and cheap raw materials, high porosity, large specific surface area, and wide sources, and has great development potential in the removal of water pollutants. Although biochar has many advantages, it produces by-products in the pyrolysis process, resulting in the reduction of specific surface area and functional groups of biochar, which further weakens the adsorption capacity of biochar to substances. Therefore, the performance of biochar needs to be improved by means of doping and modification [12].

To sum up, in order to improve the adsorption capacity of biochar, the biochar-graphene composite is prepared by one-step dip coating. In this research, a scanning electron microscope, X-ray photoelectron, spectrum analyzer, surface area meter, and other characterization equipment and techniques are used to analyze and characterize the morphology and element composition of biochar-graphene composites. Finally, the adsorption kinetics and adsorption isotherm results are analyzed. This research aims to provide a good idea for the application of BG composites in the field of environmental protection.

\section{Methods}

\subsection{Experimental Materials and Equipment}

The main reagents used in this experiment are shown in Table 1.

The main experimental instruments used in this research were: water bath (model: S312-40; manufacturer: Shanghai Shensheng Technology Co., LTD.; Shanghai, China); centrifuge (model: H-1850; manufacturer: Dongwang Instrument Co., LTD.; Changsha, China); ultrasonic instrument (model: SCIENTZ-IID; manufacturer: Ningbo Xinzhi Biotechnology Co., LTD.; Ningbo, China); pH meter (model: STARTER 3C; manufacturer: Ohaus (Shanghai) Co., LTD.; Shanghai, China); water bath constant temperature oscillator (model: SHY-2A; manufacturer: Changzhou Putian Instrument Manufacturing Co., LTD.; Changzhou, China); ultrasonic cleaning instrument (model: SB252-12D; manufacturer: Ningbo Xinzhi Biotechnology Co., LTD.; Ningbo, China); magnetic agitator (model: S312-40; manufacturer: Shanghai Shensheng Technology Co., LTD.; Shanghai, China); electronic balance (model: CAV214C; manufacturer: Ohaus (Shanghai) Co., LTD.; Shanghai, China); electric blast dryer (model: DHG-9023A; manufacturer: Shanghai precision experimental equipment co., LTD.; Shanghai, China); water bath constant temperature oscillator (model: SHY-2A; manufacturer: Changzhou Putian Instrument Manufacturing Co., LTD.; Changzhou, China); tubular electric furnace 
(model: SK-G06123K; manufacturer: Tianjin Zhonghuan Experimental Electric Furnace Co., LTD.; Tianjin, China); transmission electron microscope (model: JEM-1230; Tianjin Zhonghuan Experimental Electric Furnace Co., LTD.; Tianjin, China); Infrared Spectrum (model: Spectrum One; manufacturer: PerkinElmer; Waltham, Massachusetts, USA); X-ray diffractometer (model: D/max-2500; manufacturer: Rigaku; Tokyo, Japan); specific surface and aperture distribution analyzer (model: Autosorb-1; manufacturer: Quantachrome Instruments; Florida, USA); UV spectrophotometer (model: UV-2350; manufacturer: Shimadzu; Shimadu, Japan).

Table 1. The reagent used in this experiment.

\begin{tabular}{|c|c|c|c|}
\hline $\begin{array}{c}\text { The Name of the } \\
\text { Reagent }\end{array}$ & $\begin{array}{l}\text { Chemical } \\
\text { Equation }\end{array}$ & Purity & Manufacturer \\
\hline Graphite powder & $\mathrm{C}$ & Analytical pure & $\begin{array}{l}\text { Qingdao Tianyuan Da Graphite } \\
\text { Co. LTD }\end{array}$ \\
\hline Potassium permanganate & $\mathrm{KMnO}_{4}$ & Analytical pure & $\begin{array}{c}\text { Hubei Wanye Pharmaceutical Co. } \\
\text { LTD }\end{array}$ \\
\hline Phosphorus pentoxide & $\mathrm{P}_{2} \mathrm{O}_{5}$ & Analytical pure & $\begin{array}{c}\text { Shanghai Alighting Biochemical } \\
\text { Technology Co. LTD }\end{array}$ \\
\hline Potassium dichromate & $\mathrm{Cr}_{2} \mathrm{~K}_{2} \mathrm{O}_{7}$ & Analytical pure & $\begin{array}{c}\text { Shanghai Alighting Biochemical } \\
\text { Technology Co. LTD }\end{array}$ \\
\hline Sodium nitrate & $\mathrm{NaNO}_{3}$ & Analytical pure & $\begin{array}{l}\text { Hebei Xuxing New Energy } \\
\text { Technology Co. LTD }\end{array}$ \\
\hline $\begin{array}{l}\text { Concentrated sulfuric } \\
\text { acid }\end{array}$ & $\mathrm{H}_{2} \mathrm{SO}_{4}$ & Guaranteed reagent & $\begin{array}{c}\text { Zhengzhou Longda Chemical Co. } \\
\text { LTD }\end{array}$ \\
\hline Hydrogen peroxide & $\mathrm{H}_{2} \mathrm{O}_{2}$ & Analytical pure & $\begin{array}{c}\text { Sino Pharma Chemical Reagent } \\
\text { Co. LTD }\end{array}$ \\
\hline Potassium persulfate & $\mathrm{K}_{2} \mathrm{~S}_{2} \mathrm{O}_{8}$ & Analytical pure & $\begin{array}{c}\text { Jinan Zhendong Chemical Co. } \\
\text { LTD }\end{array}$ \\
\hline Sodium chloride & $\mathrm{NaCl}$ & Analytical pure & $\begin{array}{l}\text { Zhengzhou Chunqiu Chemical Co. } \\
\text { LTD }\end{array}$ \\
\hline Nitric acid & $\mathrm{HNO}_{3}$ & Guaranteed reagent & $\begin{array}{l}\text { Sino Pharma Chemical Reagent } \\
\text { Co. LTD } \\
\end{array}$ \\
\hline Sodium hydroxide & $\mathrm{NaOH}$ & Analytical pure & $\begin{array}{c}\text { Nanjing Chemical Reagent Co. } \\
\text { LTD }\end{array}$ \\
\hline $\begin{array}{c}\text { Concentrated } \\
\text { hydrochloric acid }\end{array}$ & $\mathrm{HCl}$ & Guaranteed reagent & $\begin{array}{l}\text { Sino Pharma Chemical Reagent } \\
\text { Co. LTD }\end{array}$ \\
\hline $\begin{array}{l}\text { Diphenyl carbonyl } \\
\text { dihydrazine }\end{array}$ & $\mathrm{C}_{13} \mathrm{H}_{14} \mathrm{~N}_{4} \mathrm{O}$ & Analytical pure & $\begin{array}{c}\text { Nanjing Chemical Reagent Co. } \\
\text { LTD }\end{array}$ \\
\hline Acetone & $\mathrm{CH}_{3} \mathrm{COCH}_{3}$ & Guaranteed reagent & $\begin{array}{l}\text { Sino Pharma Chemical Reagent } \\
\text { Co. LTD }\end{array}$ \\
\hline Dimethyl phthalate & $\mathrm{C}_{10} \mathrm{H}_{10} \mathrm{O}_{4}$ & Analytical pure & $\begin{array}{c}\text { Shanghai Alighting Biochemical } \\
\text { Technology Co., LTD }\end{array}$ \\
\hline Diethyl phthalate & $\mathrm{C}_{12} \mathrm{H}_{14} \mathrm{O}_{4}$ & Analytical pure & $\begin{array}{c}\text { Shanghai Alighting Biochemical } \\
\text { Technology Co., LTD }\end{array}$ \\
\hline Dibutyl phthalate & $\mathrm{C}_{16} \mathrm{H}_{22} \mathrm{O}_{4}$ & Analytical pure & $\begin{array}{c}\text { Shanghai Alighting Biochemical } \\
\text { Technology Co., LTD }\end{array}$ \\
\hline
\end{tabular}

\subsection{Synthesis of the $G O$}

In this research, the improved Hummer method was used to prepare GO [13-16]. The preparation process was as follows: First, $40 \mathrm{~mL}$ of concentrated sulfuric acid was cooled at $0{ }^{\circ} \mathrm{C}$, and then $8.50 \mathrm{~g}$ of $\mathrm{K}_{2} \mathrm{~S}_{2} \mathrm{O}_{8}$ was added to fully stir and dissolve it. Then, $8.50 \mathrm{~g}$ p pentoxide powder was added under full 
stirring and dissolution. Then, $200 \mathrm{~g}$ of graphite powder was added to the mixed solution for water bath heating reaction at $80^{\circ} \mathrm{C}$ for $4 \mathrm{~h}$. After the reaction, deionized water was used for cooling, and $12 \mathrm{~h}$ after the reaction, deionized water was used for washing to neutral. After vacuum drying at $60^{\circ} \mathrm{C}$, the product was graphite oxide, and the pre-oxidation stage was completed. During the oxidation stage, a mixture of pre-oxidized powder $(10 \mathrm{~g})$, potassium permanganate $(40 \mathrm{~g})$, and sodium nitrate $(5 \mathrm{~g})$ was added to $98 \%$ concentrated sulfuric acid $(230 \mathrm{~mL})$. The reaction condition was $35^{\circ} \mathrm{C}$ for $2 \mathrm{~h}$. The resulting product was cleaned and oscillated at $90{ }^{\circ} \mathrm{C}$ for $1 \mathrm{~h}$. The deionized water was added. Then, it was oscillated for $2 \mathrm{~h}$ at room temperature and cleaned with $10 \% \mathrm{HCl}$ to neutral. Ultrasonic cleaning was then carried out for $2 \mathrm{~h}$ at $50{ }^{\circ} \mathrm{C}$ to yield a yellowish GO dispersion. The technical roadmap of the preparation process is shown in Figure 1.

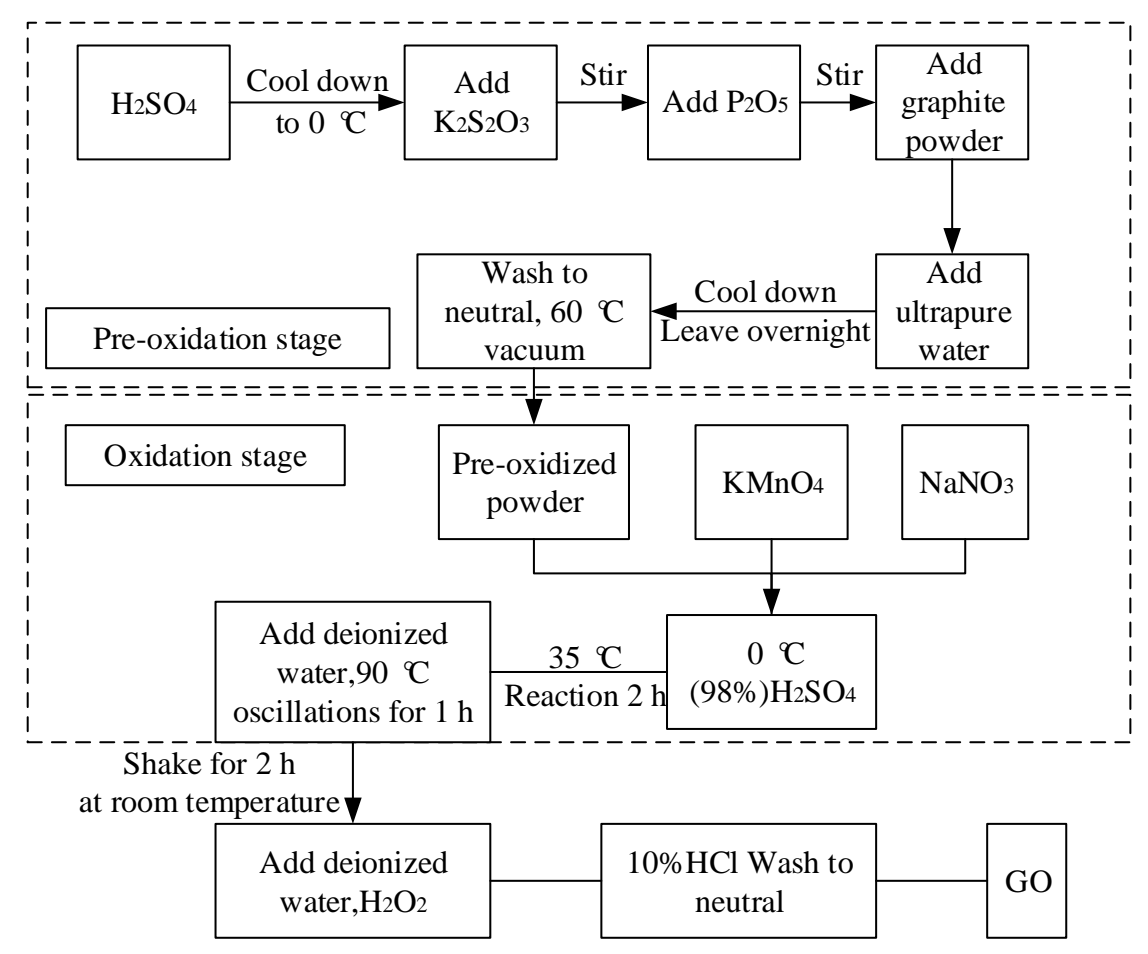

Figure 1. Technical roadmap for the preparation of graphene oxide (GO) dispersion.

\subsection{Preparation of BG Composites Based on One-Step Dip Coating Method}

The biochar obtained in this research was mainly from wood. Two kinds of biochar and BG composites were prepared by wood bio pyrolysis at different temperatures.

\subsubsection{Preparation of Biochar}

The specific preparation method was as follows: Firstly, the obtained wood chips were washed with water, dried overnight in a $105^{\circ} \mathrm{C}$ oven, and then air-dried for 2 days. The raw biochar was then ground through a high-speed rotary machine to obtain the powdered biochar, which could pass through a $100 \mathrm{~mm}$ mesh screen. Then, $100 \mathrm{~mm}$ biochar powder was placed in a ceramic pot after being sieved and covered tightly. Pyrolysis was conducted in a tube furnace, and the pyrolysis conditions were set at $300{ }^{\circ} \mathrm{C}$ and $600{ }^{\circ} \mathrm{C}$, respectively. Pyrolysis was carried out for $2 \mathrm{~h}$ under oxygen restriction conditions to avoid calcination of biochar in the presence of oxygen. During the pyrolysis process, the heating rate was controlled at $5{ }^{\circ} \mathrm{C} / \mathrm{min}$ for slow pyrolysis to produce more solid residues (biochar). Biochar samples were washed with deionized water for $24 \mathrm{~h}$ under magnetic agitation to remove the water-soluble inorganic materials. It was washed repeatedly until the $\mathrm{pH}$ was neutral, and dried in the drying box. Finally, biochar was obtained through a filter of $0.22 \mu \mathrm{m}$. To control the size of biochar, the charred solids were passed through a $500 \mathrm{~mm}$ sieve, and the resulting product was a biochar sample. 
The products obtained at different temperatures were labeled as $\mathrm{B}_{300}$ and $\mathrm{B}_{600}$, respectively, with the subscripts for each indicating different combustion temperatures.

\subsubsection{Preparation of BG Composites}

In this research, BG composites were prepared by one-step dip coating. First, $20 \mathrm{~g}$ biochar was immersed in $200 \mathrm{~mL}$ ( $0.1 \%$ by mass) of the GO nanometer suspension prepared in this research and stirred for 1 hour. The initial mass loss during biochar treatment with GO suspension was less than $1 \%$ due to the fact that biochar tends to adhere to the wall during the agitation process. The mixture was then dried in an oven at $80^{\circ} \mathrm{C}$ for $3 \mathrm{~h}$. The pre-treated biochar was pyrolyzed in a muffle furnace at $300^{\circ} \mathrm{C}$ and $600^{\circ} \mathrm{C}$ to produce BG composites. The sample was then washed (four times) with deionized water to remove the water-soluble inorganic material. The resulting products were labeled as $\mathrm{BG}_{300}$ and $\mathrm{BG}_{600}$, respectively. Similarly, the subscripts for each indicate different combustion temperatures.

\subsection{Characterization of Biochar and BG Composites}

In this research, the morphology characteristics of biochar and BG composites were characterized by means of scanning electron microscopy (SEM), transmission electron microscopy (TEM), and X-ray photoelectron spectroscopy (XPS). During the morphology characterization, the samples of biochar and biochar-graphene composite materials needed to be dried for the SEM test, and then the powder samples were fixed on the sample stage with conductive adhesive. After $30 \mathrm{~s}$ of gold spraying, the internal morphology and element composition of the samples were observed by transmission electron microscopy and XPS for analysis. XPS enabled quantitative and qualitative analysis of the elements indicated by biochar and BG composites. Test results were processed by XPSPEAK4.1 analysis software (Manufacturer: UK Kratos Company; Manchester, England) [17-20].

In this research, specific surface area (SA)/pore size was compared, and a specific surface area/pore size analyzer was used to determine the specific surface area and pore size distribution of biochar and biochar-graphene composites. The samples were degassed at $100{ }^{\circ} \mathrm{C}$ before the nitrogen isothermal adsorption-desorption test [21,22].

Positron annihilation works by using spin antiparallel p-Ps in which the electrons annihilate in the form of $2 \gamma$. It lasts a very short time in vacuum, about $125 \mathrm{ps}$. The positive and negative electrons in the spin-parallel o-Ps annihilate in the form of $3 \gamma$, and their vacuum existence time is 1000 times longer than that of p-Ps, which is about $142 \mathrm{~ns}$. However, in all condensed matter, the annihilation life of o-Ps has been found to be shorter than its intrinsic life in vacuum because in many materials, when o-s interacts with molecules or atoms, the positrons pick up a spin-antiparallel electron from the surrounding medium and annihilate with it in the form of $2 \gamma$; this process is called "pick up annihilation". This process is the conversion of o-Ps to p-Ps annihilation, reducing the annihilation lifetime to a few nanometers.

\subsection{Adsorption Kinetics and Isothermal Model}

The adsorption dynamic isotherms of phthalates (PAEs) were obtained by batch equilibrium experiments. The determination process was as follows: Dimethyl phthalate (DMP), diethyl phthalate (DEP), and dibutyl phthalate (DBP) were dissolved in methanol as a reserve solution and then diluted to a solution containing $0.02 \mathrm{~mol} \mathrm{NaCl}$ (maintaining a constant ion concentration) and $200 \mathrm{mg} / \mathrm{L} \mathrm{NaN}$ $(\mathrm{pH}=7.0 \pm 1)$. The percentage by volume of methanol had to be kept below the volume ratio of $0.10 \%$ to minimize the role of the cosolvent. For DMP and DEP, adsorption experiments were performed in an $8 \mathrm{~mL}$ glass bottle with a Teflon-lined screw cap. Adsorption kinetics was studied with the initial concentration of DMP and DEP at $10 \mathrm{mg} / \mathrm{L}$. The adsorption kinetics of DBP was studied at an initial concentration of $4 \mathrm{mg} / \mathrm{L}$. The solid/water ratio was $5 \mathrm{mg}$ at $30{ }^{\circ} \mathrm{C}$ and $3 \mathrm{mg}$ at $600{ }^{\circ} \mathrm{C}$. Residual concentrations in a series of independent samples were measured from start to $72 \mathrm{~h}$. The isotherm experiments are carried out with different solid/water ratios. For DMP and DEP, $5 \mathrm{mg}$ and $3 \mathrm{mg}$ biochar and $8 \mathrm{~mL}$ solution were added to each vial, respectively. For DBP, $5 \mathrm{mg}$ and $3 \mathrm{mg}$ of biochar 
were added to the $15 \mathrm{ml}$ vial and place in the dark. At room temperature $\left(25 \pm 1^{\circ} \mathrm{C}\right)$, it was shaken by a rotating shaker (rotating at $120 \mathrm{RPM} / \mathrm{min}$ ) according to the balance time. During this period, all phthalates (DMP, DEP, DBP) were stable, and no significant degradation was observed. All vials were centrifuged at $2500 \mathrm{r} / \mathrm{min}$ for $10 \mathrm{~min}$, and then the concentrations of DMP, DEP, and DBP of each supernatant were determined by HPLC.

In order to provide a more in-depth and reliable basis for the study of adsorption mechanism, the adsorption equilibrium isotherm was studied in detail. The temperature in the adsorption process was mainly affected by two aspects. The first was that as the temperature increased, the viscosity of the solution decreased, and the diffusion rate of the adsorbent membrane and the internal pores of the adsorbent particles increased. The second was that changing the temperature changed the adsorption balance of a specific adsorbent [23-25]. Therefore, in order to study the isothermal adsorption characteristics of BG composites, two typical isothermal adsorption models were used to fit the isothermal adsorption data. Each experiment was repeated three times, and then the average was taken to plot a curve.

The Langmuir isothermal model assumes that the adsorption process is adsorption in the gas-solid monolayer, and the expression is as follows:

$$
\frac{C_{e}}{q_{e}}=\frac{1}{k_{L} q_{\max }}+\frac{C_{e}}{q_{\max }^{2}}
$$

where $C_{e}$ is the equilibrium concentration of phthalates; $q_{\max }$ denotes the maximum adsorption capacity of the adsorbent on phthalate; $q_{e}$ is the adsorption capacity of unit mass dry adsorbent to phthalate ester at adsorption equilibrium; and $K_{L}$ represents the Langmuir constant related to the affinity of the adsorption site [26].

The Freundlich isothermal model is a simulation of the adsorption process occurring in heterogeneous layers without considering adsorption saturation, and the expression is as follows:

$$
\ln q_{e}=\ln K_{F}+\frac{1}{N} \ln C_{e}
$$

where $K_{F}$ is the Freundlich constant related to adsorption capacity, and $N$ represents the constant related to the strength of adsorption capacity; when $\mathrm{n}<1$, this indicates that adsorption is very difficult; when $1<N<2$, it indicates that adsorption is relatively difficult; when $2<N<10$, it indicates that the adsorption strength is high and the adsorption is easy [27].

\section{Results}

\subsection{Structural Characterization of Biochar and BG Composites}

Figure 2 shows SEM images of biochar and BG composites at $300^{\circ} \mathrm{C}$ and $600{ }^{\circ} \mathrm{C}$. Figure 3 shows TEM images of biochar and BG composites at $300^{\circ} \mathrm{C}$ and $600^{\circ} \mathrm{C}$. It was found from the SEM photos of biochar that biochar usually exhibited rough and porous properties at $300^{\circ} \mathrm{C}$, while the SEM photos of biochar with pores clearly show the attached graphene layer on the surface of biochar with pores. SEM and TEM results show that the slow pyrolysis could completely fuse graphene with biochar without changing the original morphology of graphene. TEM images show that graphene was transparent and slightly concentrated in biochar at either $300^{\circ} \mathrm{C}$ or $600^{\circ} \mathrm{C}$. At a temperature of $300^{\circ} \mathrm{C}$, the base surface of graphene was not completely ordered, while a temperature greater than $600^{\circ} \mathrm{C}$ destroyed the residual $\mathrm{O}_{2}$ group, resulting in a large number of defects. In addition, the folds of graphene were relaxed and evenly distributed, peeling randomly on the surface of biochar. 

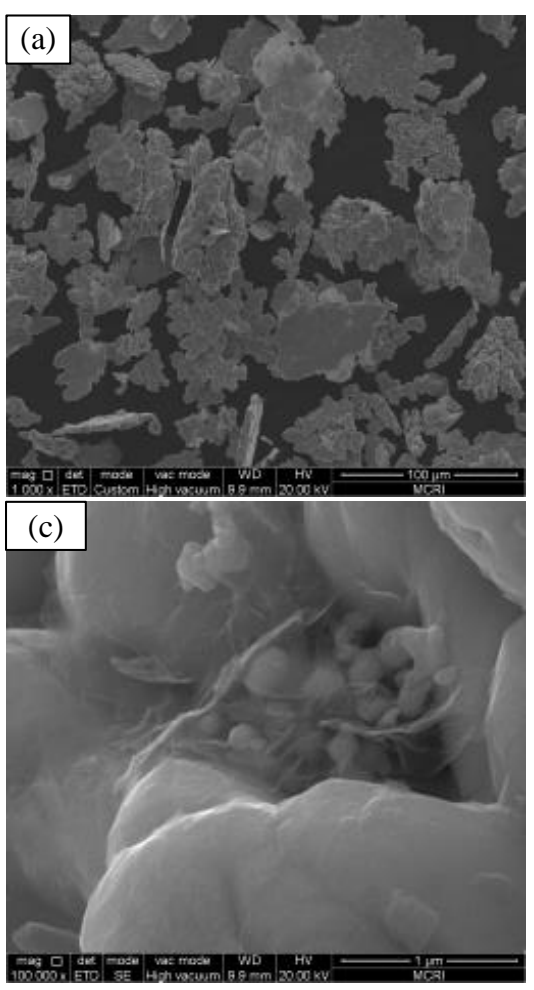
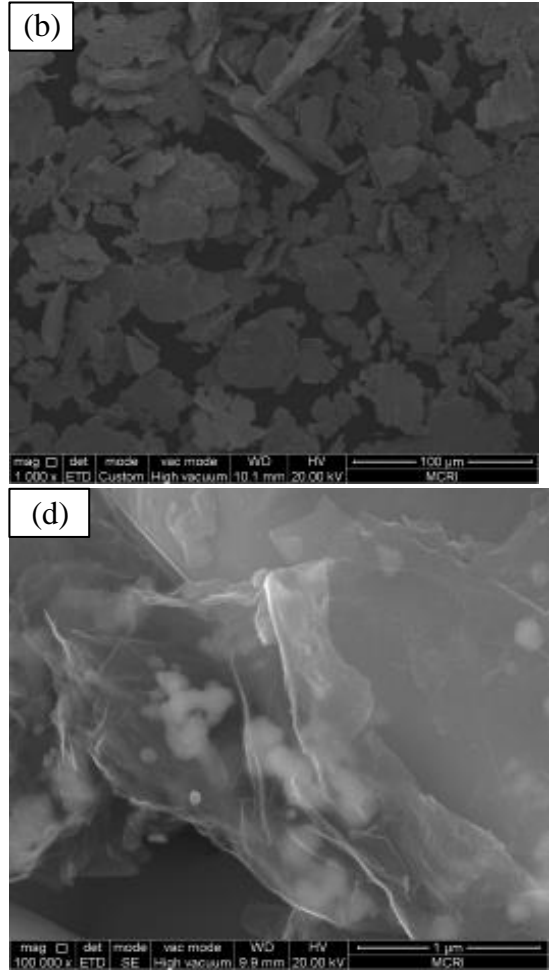

Figure 2. SEM images of biochar and biochar-graphene (BG) composites at $300{ }^{\circ} \mathrm{C}$ and $600{ }^{\circ} \mathrm{C}$. (a) $\mathrm{B}_{300}$; (b) $\mathrm{B}_{600} ;$ (c) $\mathrm{BG}_{300} ;$ (d) $\mathrm{BG}_{600}$.

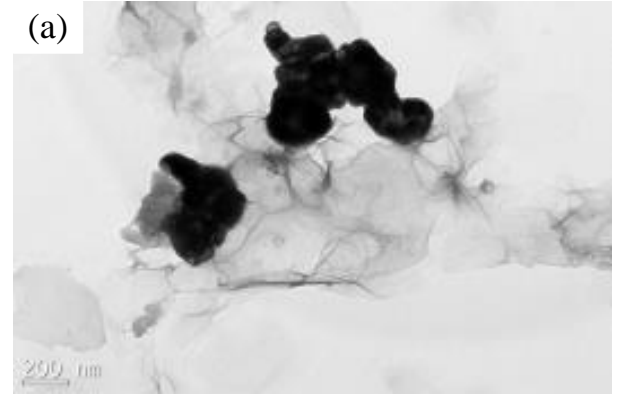

(c)

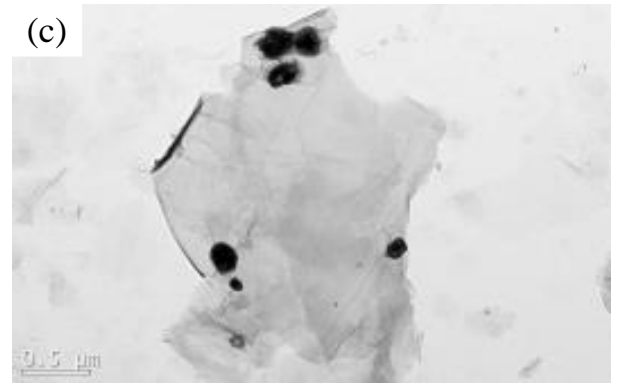

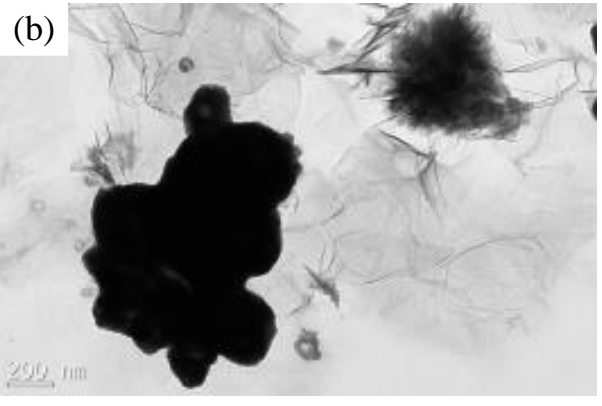

(d)

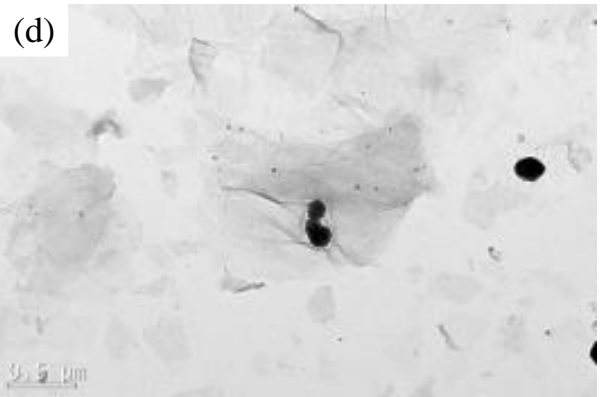

Figure 3. TEM images of biochar and BG composites at $300^{\circ} \mathrm{C}$ and $600{ }^{\circ} \mathrm{C}$ (a) $\mathrm{B}_{300}$; (b) $\mathrm{B}_{600}$; (c) $\mathrm{BG}_{300}$; (d) $\mathrm{BG}_{600}$.

Figure 4 shows the isothermal adsorption-desorption curves and pore size distribution curves of biochar and $\mathrm{BG}$ composites based on $\mathrm{N}_{2}$ and $\mathrm{CO}_{2}$. Table 2 shows the specific surface area and pore volume based on XPS results. Figure 4 a shows that $\mathrm{N}_{2}-\mathrm{SA}$ of biochar increased with the increase of pyrolysis temperature (according to XPS results, $\mathrm{B}_{300}\left(8.4 \mathrm{~m}^{2} \mathrm{~g}^{-1}\right)<\mathrm{B}_{600}\left(221.3 \mathrm{~m}^{2} \mathrm{~g}^{-1}\right)$ ). Adding graphene could increase the specific surface area of biochar (according to XPS results, $\mathrm{BG}_{300}\left(11.01 \mathrm{~m}^{2} \mathrm{~g}^{-1}\right)<$ $\left.\mathrm{BG}_{600}\left(251.82 \mathrm{~m}^{2} \mathrm{~g}^{-1}\right)\right)$. The reason is that the presence of graphene and graphite regions provided 
some potential adsorption sites for the incorporation of biochar-graphene composites, which also indicated that the aromatization of biochar increased with the increase of porosity $[28,29]$. As shown in Figure $4 \mathrm{~b}$, the $\mathrm{CO}_{2}$-SA of biochar also increased from $117.70 \mathrm{~m}^{2} \mathrm{~g}^{-1}$ to $367.71 \mathrm{~m}^{2} \mathrm{~g}^{-1}$ at $300{ }^{\circ} \mathrm{C}$. Similarly, BG composites increased from $121.94 \mathrm{~m}^{2} \mathrm{~g}^{-1}$ to $455.98 \mathrm{~m}^{2} \mathrm{~g}^{-1}$, which indicated that micropores already existed in $\mathrm{B}_{300}$ and $\mathrm{BG}_{300}$ biochar, and the affinity with graphite was higher in $\mathrm{CO}_{2}-\mathrm{SA}$ than in $\mathrm{N}_{2}-\mathrm{SA}$. With the increase of pyrolysis temperature, the pore size of $\mathrm{BG}_{600}$ increased significantly, indicating that there were more micropores in $\mathrm{BG}_{600}$ than in $\mathrm{B}_{600}$. The difference between $\mathrm{CO}_{2}-\mathrm{SA}$ and $\mathrm{N}_{2}-\mathrm{SA}$ further indicated that the structure of biochar and biochar-graphene composites did not change at the pyrolysis temperature of $300^{\circ} \mathrm{C}$, while the structure of biochar-graphene composites at $600^{\circ} \mathrm{C}$ had a nanopore structure, which gradually condensed into smaller aromatic units.

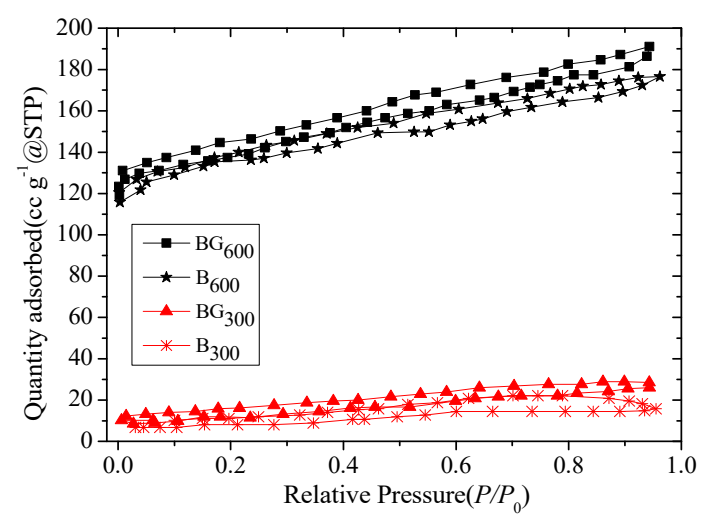

(a)

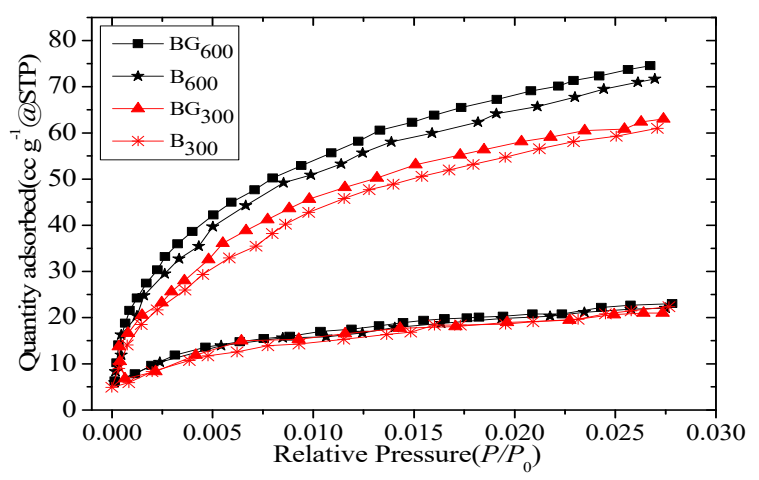

(b)

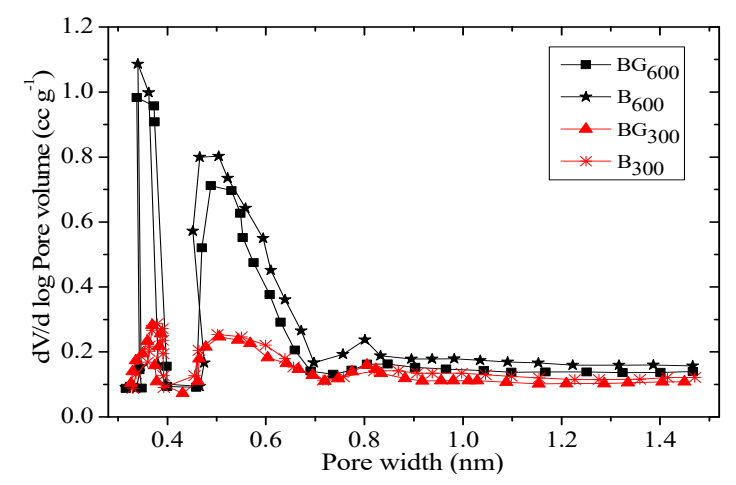

(c)

Figure 4. The adsorption-desorption curves and pore size distribution curves of biochar and BG composites based on $\mathrm{N}_{2}$ and $\mathrm{CO}_{2}$. (a) $\mathrm{N}_{2} ;$ (b) $\mathrm{CO}_{2}$; (c) Pole distribution curve. 
Table 2. Specific surface area and pore volume based on XPS results.

\begin{tabular}{cccccc}
\hline \multirow{2}{*}{$\begin{array}{c}\text { Names of } \\
\text { Samples }\end{array}$} & \multicolumn{2}{c}{ BET-N $_{\mathbf{2}}{ }^{*}$} & \multicolumn{2}{c}{ BET-CO $_{\mathbf{2}}{ }^{*}$} & SA \\
\cline { 2 - 4 } & $\mathbf{S A} /\left(\mathbf{m}^{\mathbf{2}} \mathbf{g}^{-\mathbf{1}}\right)$ & $\mathbf{P V}\left(\mathbf{m}^{\mathbf{2}} \mathbf{g}^{-\mathbf{1}}\right)$ & $\mathbf{S A}\left(\mathbf{m}^{\mathbf{2}} \mathbf{g}^{-\mathbf{1}}\right)$ & $\mathbf{P V}\left(\mathbf{m}^{\mathbf{2}} \mathbf{g}^{-\mathbf{1}}\right)$ & \\
\hline $\mathrm{B}_{300}$ & 8.40 & 0.014 & 117.70 & 0.055 & 109 \\
\hline $\mathrm{BG}_{300}$ & 11.01 & 0.023 & 121.94 & 0.057 & 110 \\
\hline $\mathrm{B}_{600}$ & 221.3 & 0.037 & 367.71 & 0.183 & 165 \\
\hline $\mathrm{BG}_{600}$ & 251.82 & 0.044 & 455.98 & 0.182 & 139 \\
\hline
\end{tabular}

Note: SA stands for specific surface area; PV represents the pore volume; BET stands for specific surface area test, which is the combination of the first capital of names of three scientists. ${ }^{*}$ indicates that the BET method is used to measure the surface area and pore volume.

As shown in Figure 5, the relative free volume fraction decreased with the increase of graphene concentration, and $\mathrm{N}_{2}$-SA of biochar at different temperatures increased with the increase of pyrolysis temperature (according to positron annihilation results: $\mathrm{B}_{300}<\mathrm{B}_{600}$ ). The addition of graphene could increase the specific surface area of biochar (according to positron annihilation results: $\mathrm{BG}_{300}<\mathrm{BG}_{600}$ ). The reason is that the relative free volume fraction decreased with the increase of graphene concentration, which means that the overall effect of graphene limited the mobility of biochar molecular chains. The accumulation density of biochar molecules increased, which increased the surface area of graphene composites. Therefore, the positron annihilation result was consistent with the XPS result.

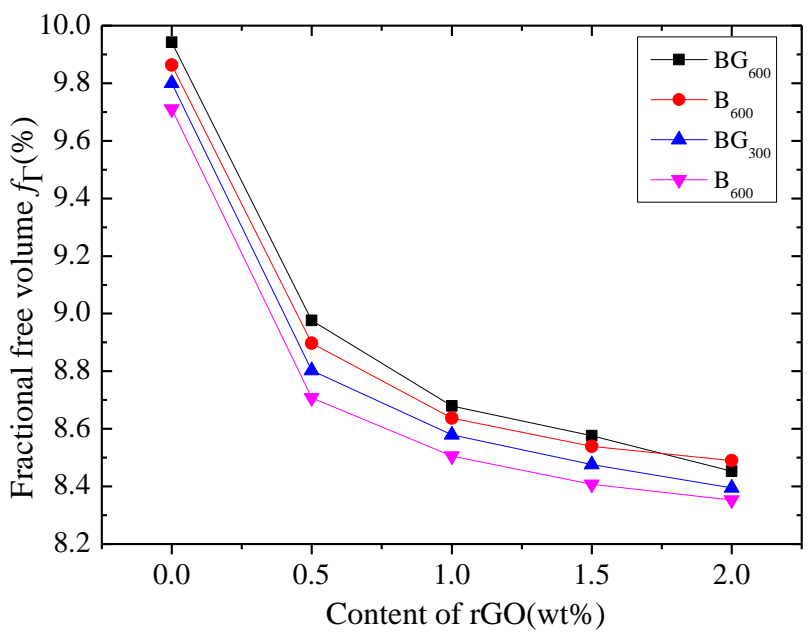

Figure 5. Positron annihilation spectra of the free volume fraction of graphene.

\subsection{Adsorption Kinetics of Biochar and BG Composites}

The adsorption kinetics of phthalates on biochar and BG composites were studied by pseudo-primary and pseudo-secondary kinetic models. Figure 6 shows the adsorption kinetics curves of phthalates on biochar and BG composites. Table 3 shows the kinetic parameters of adsorption of biochar and biochar-graphene composites on dimethyl phthalate (DMP), diethyl phthalate (DEP), and dibutyl phthalate (DBP). As concluded from Figure 5 and Table 3, for both biochar materials and biochar-graphene composites, the adsorption rate of biochar increased rapidly within the first $24 \mathrm{~h}$ and reached the adsorption equilibrium within about $48 \mathrm{~h}$. The correlation coefficient $\left(\mathrm{r}_{\mathrm{adj}}{ }^{2}\right)$ of the pseudo-secondary model was higher than that of the pseudo-primary model, which indicated that the pseudo-secondary model had higher adsorption capacity. The adsorption rate of biochar increased rapidly in the first $24 \mathrm{~h}$ and reached adsorption equilibrium in about $48 \mathrm{~h}$. When the temperature dropped from $600{ }^{\circ} \mathrm{C}$ to $300{ }^{\circ} \mathrm{C}$, the adsorption rate of biochar decreased accordingly. This result suggests that the porosity and structural differences of biochar may lead to diffusion interaction time, which delays the adsorption of the initial PAEs. Similarly, in biochar-graphene composites, a trend of 
decreasing adsorption rate with temperature appeared, indicating that graphene provided additional diffusion for initial PAEs adsorption. These results show that under the combined action of temperature and graphene, the higher the mobility of PAE molecules, the faster they would approach the surface of biochar in a shorter time and have a higher initial adsorption rate. Therefore, for the adsorption effect, $\mathrm{B}_{300}<\mathrm{BG}_{300}<\mathrm{B}_{600}<\mathrm{BG}_{600}$. When the adsorption equilibrium was reached, the adsorption effect of $\mathrm{BG}_{600}$ was the best, especially the adsorption amount of DMP, which was $35.2 \mathrm{mg} / \mathrm{g}$; the adsorption rates of DEP and DBP were $26.4 \mathrm{mg} / \mathrm{g}$ and $25.1 \mathrm{mg} / \mathrm{g}$, respectively.

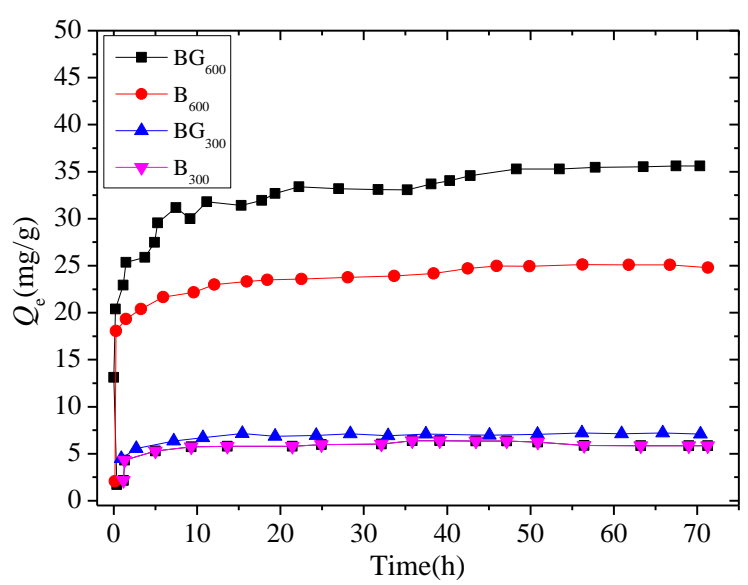

(a) DMP

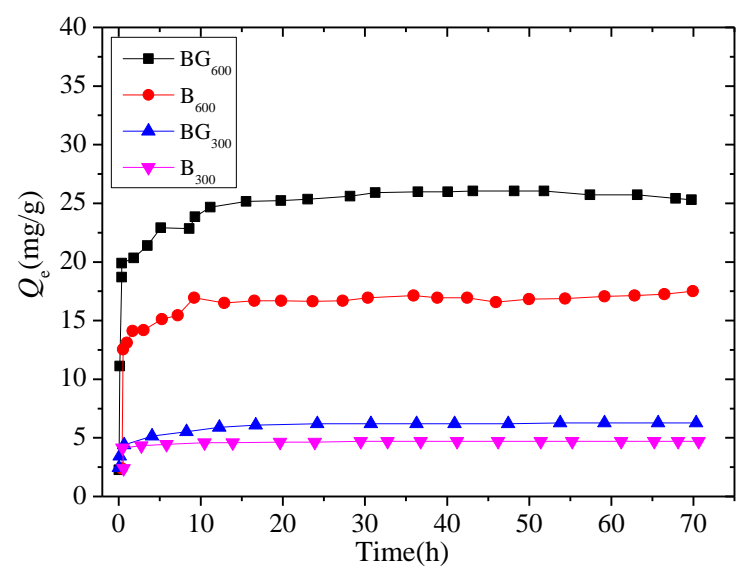

(b) DEP

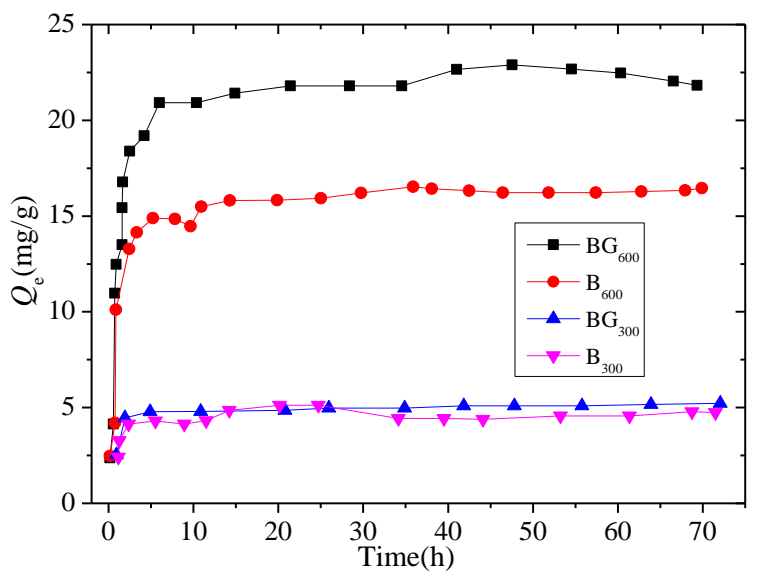

(c) $\mathrm{DBP}$

Figure 6. Cont. 


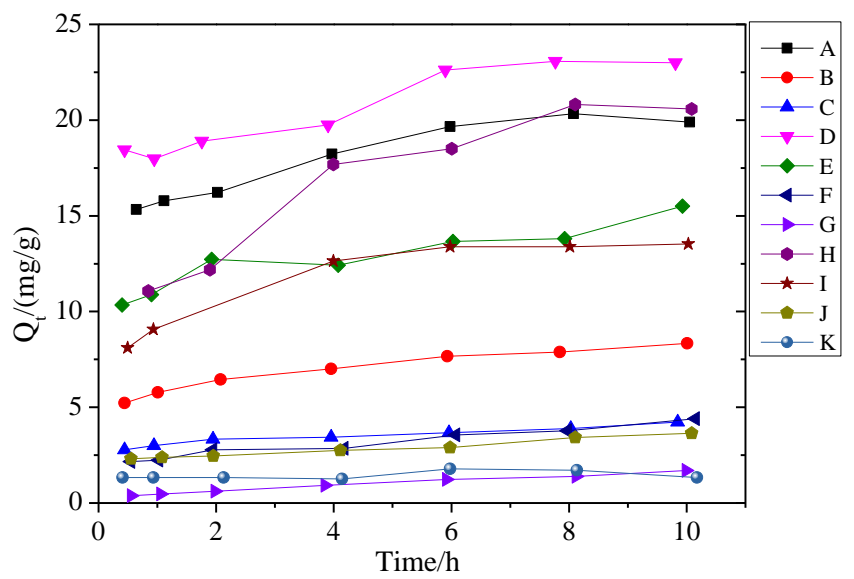

(d)

Figure 6. Adsorption dynamic curves of biochar and biochar-graphene composites for dimethyl p-phthalate (DMP), diethyl phthalate (DEP), and dibutyl phthalate (DBP); (a) DMP;(b) DEP;(c) DBP; (d) is the absorption rate change of o-benzene by biochar-graphene composites at different temperatures (A-D represent the absorption rate of $\mathrm{BG}_{600}, \mathrm{~B}_{600}, \mathrm{BG}_{300}$, and $\mathrm{B}_{300}$ for DMP; $\mathrm{E}-\mathrm{F}$ represents the DEP absorption rate of $\mathrm{BG}_{600}, \mathrm{~B}_{600}, \mathrm{BG}_{300}$, and $\mathrm{B}_{300}$. $\mathrm{H}-\mathrm{K}$ represent the absorption rate of $\mathrm{BG}_{600}, \mathrm{~B}_{600}, \mathrm{BG}_{300}$, and $\mathrm{B}_{300}$ for DBP).

Table 3. Kinetic parameters of adsorption of DMP, DEP, and DBP by biochar and BG composites.

\begin{tabular}{|c|c|c|c|c|c|c|c|c|c|c|}
\hline \multirow[t]{2}{*}{ Phthalate } & \multirow{2}{*}{$\begin{array}{l}\text { Names of } \\
\text { Samples }\end{array}$} & \multicolumn{3}{|c|}{$\begin{array}{l}\text { Pseudo First Order } \\
\text { Dynamic Model }\end{array}$} & \multicolumn{3}{|c|}{$\begin{array}{l}\text { Pseudo Second Order } \\
\text { Dynamic Model }\end{array}$} & \multicolumn{3}{|c|}{ Internal Diffusion Model } \\
\hline & & $Q_{\mathrm{e}} /(\mathrm{mg} / \mathrm{g})$ & $k_{1}\left(\mathrm{~h}^{-1}\right)$ & $r_{\mathrm{adj}}^{2}$ & $Q_{\mathrm{e}} /(\mathrm{mg} / \mathrm{g})$ & $k_{1}\left(\mathrm{~h}^{-1}\right)$ & $r_{\mathrm{adj}}^{2}$ & $Q_{\mathrm{e}} /(\mathrm{mg} / \mathrm{g})$ & $k_{1}\left(\mathrm{~h}^{-1}\right)$ & $r_{\text {adj }}^{2}$ \\
\hline \multirow{4}{*}{ DMP } & $\mathrm{B}_{300}$ & 3.88 & 1.92 & 0.843 & 4.05 & 0.783 & 0.939 & 2.81 & 0.123 & 0.934 \\
\hline & $\mathrm{BG}_{300}$ & 4.09 & 1.65 & 0.794 & 4.26 & 0.542 & 0.901 & 2.81 & 0.126 & 0.976 \\
\hline & $\mathrm{B}_{600}$ & 20.15 & 1.71 & 0.821 & 20.09 & 0.127 & 0.948 & 14.76 & 0.607 & 0.876 \\
\hline & $\mathrm{BG}_{600}$ & 28.12 & 1.28 & 0.805 & 19.32 & 0.063 & 0.927 & 19.35 & 1.09 & 0.854 \\
\hline \multirow{4}{*}{ DEP } & $B_{300}$ & 2.46 & 3.49 & 0.943 & 2.37 & 3.376 & 0.982 & 2.19 & 1.036 & 0.813 \\
\hline & $\mathrm{BG}_{300}$ & 3.51 & 1.08 & 0.836 & 3.26 & 0.447 & 0.945 & 2.27 & 0.145 & 0.901 \\
\hline & $\mathrm{B}_{600}$ & 13.93 & 2.01 & 0.851 & 15.11 & 0.225 & 0.943 & 11.16 & 0.446 & 0.919 \\
\hline & $\mathrm{BG}_{600}$ & 21.74 & 2.21 & 0.787 & 21.87 & 0.142 & 0.899 & 16.89 & 0.571 & 0.883 \\
\hline \multirow{4}{*}{ DBP } & $\mathrm{B}_{300}$ & 2.41 & 2.32 & 0.837 & 2.69 & 1.38 & 0.917 & 2.07 & 0.049 & 0.712 \\
\hline & $\mathrm{BG}_{300}$ & 3.02 & 2.04 & 0.865 & 3.07 & 1.06 & 0.962 & 2.31 & 0.105 & 0.917 \\
\hline & $\mathrm{B}_{600}$ & 14.27 & 1.91 & 0.901 & 13.65 & 0.142 & 0.916 & 10.08 & 0.467 & 0.645 \\
\hline & $\mathrm{BG}_{600}$ & 19.85 & 0.52 & 0.876 & 20.04 & 0.051 & 0.963 & 10.67 & 1.21 & 0.876 \\
\hline
\end{tabular}

\subsection{Adsorption Isotherms of PAEs on BG Composites}

Figure 7 shows the isothermal adsorption curves of biochar-graphene composite materials including DMP, DEP, and DBP fitted by the Freundlich model and Langmuir model, respectively. The adsorption capacity of BG composites pyrolyzed at $300{ }^{\circ} \mathrm{C}$ was less than that of BG composites pyrolyzed at $600{ }^{\circ} \mathrm{C}$. The reason for this phenomenon was the change of specific surface area of biochar. The larger the specific surface area, the stronger the adsorption property of the composite material. The adsorption capacity of biochar-graphene composites to PAEs was absolutely higher than that of biochar at this temperature, indicating that graphene can be used as a potential site to improve adsorption. The isotherms adsorbed by PAEs were characterized by different $K_{p}$ values, while the $\mathrm{N}$ values adsorbed by a single PAE were not significantly different from each other. Therefore, the Freundlich $\mathrm{N}$ value presented a highly nonlinear trend, and the $\mathrm{K}_{\mathrm{r}}$ increased accordingly. The $\mathrm{N}$ value of the Freundlich model indicated that the surface of the BG composite was non-uniform, and the higher $\mathrm{N}$ value indicated the homogeneous surface with narrow adsorption site distribution. 


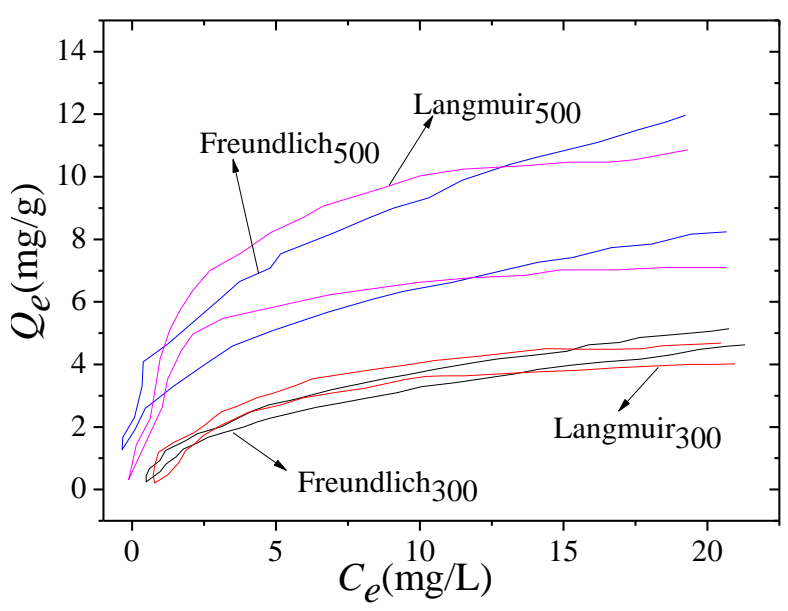

(a) DMP

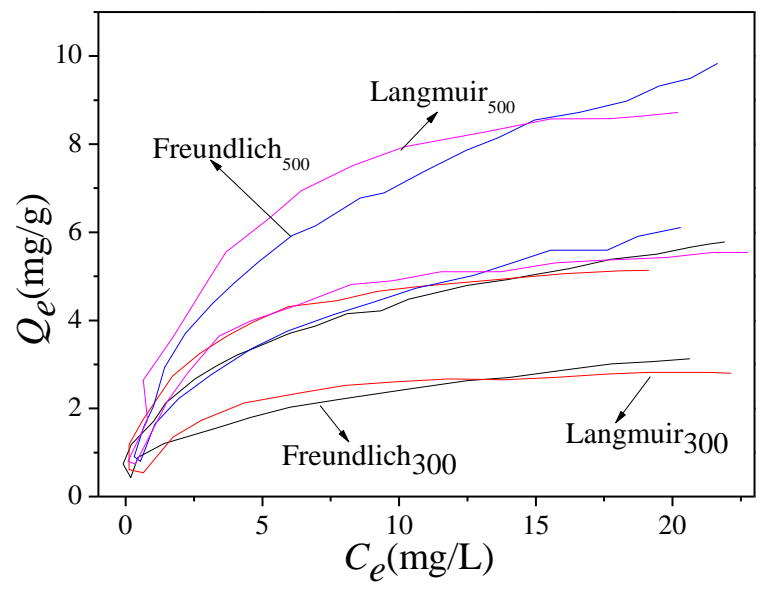

(b) DEP

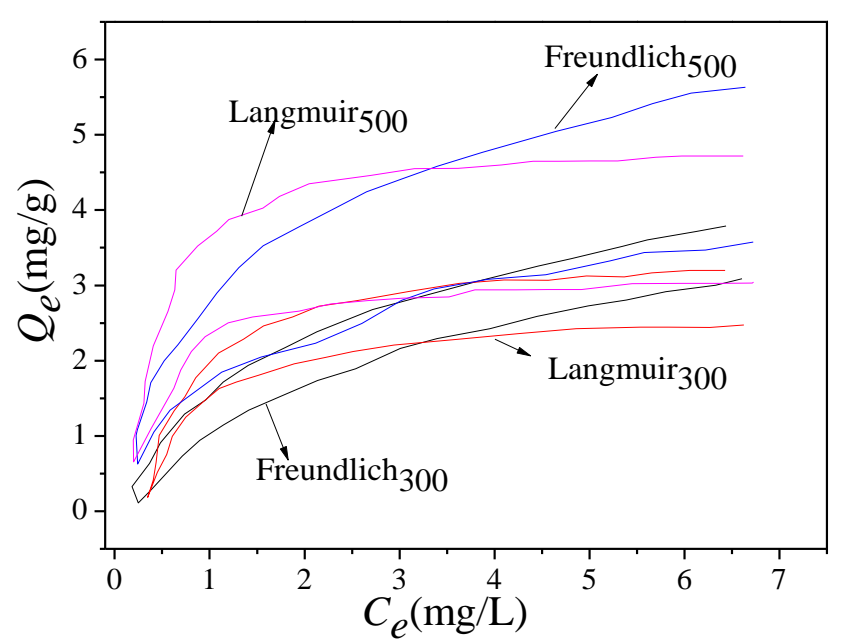

(c) DBP

Figure 7. The adsorption curves of DMP, DEP, and DBP were fitted by Freundlich model and Langmuir model, respectively; (a) DMP;(b) DEP;(c) DBP.

In this study, the adsorption properties of biocarbon-graphene composites were discussed and compared with the commonly used adsorbents, which mainly include activated carbon, chitosan, biological adsorbent, clay mineral material, modified corn cob, polymer resin, and other materials. All 
these adsorbents have abundant pore structure and surface groups to adsorb PAEs. Wang used Wutong to prepare activated carbon. After phosphoric acid modification, the porosity of activated carbon increased, the pore diameter decreased, the specific surface area increased, and the adsorption effect was better than before modification. The specific surface area of biochar prepared by the modified method was $15.9 \mathrm{~m}^{2} \mathrm{~g}^{-1}$, which was 15 times larger than that of the biochar-graphene composite prepared in this study. In addition, the study revealed that the $\mathrm{pH}$ value would affect the adsorption of adsorbent on PAEs. After the study of the adsorption effects under different $\mathrm{pH}$ values, it was found that the optimal adsorption effect was obtained when the $\mathrm{pH}$ value was 13 , and the surface of the modified activated carbon was positively charged, increasing the electrostatic adsorption effect with PAEs [30]. Moazzen et al. prepared biochar with peanut shell by the oxygen-controlled heating carbonization method. At three preparation temperatures, biochar showed different element contents. The adsorption of the two PAEs conformed to the Freundlich equation as the degree of aromatics increased with the increase of temperature. In this study, the pseudo-two-stage model of adsorption dynamic composite dynamics of biochar-graphite composites were prepared at two different temperatures [31]. Abdul et al. successfully prepared a flake biochar nanographene complex, which showed a good adsorption effect on the three PAEs. The main mechanism of adsorption on the three PAEs was different. DMP, with a relatively small molecular mass, was directly absorbed by the complex through pore diffusion. The main mechanism of DEP adsorption was $\pi-\pi$ interaction, while DBP was adsorbed by hydrophobic interaction between molecules [32]. The biochar-graphene composite prepared in this study shows the best adsorption effect on DMP in the adsorption process of three PAEs, followed by DEP and finally DBP. As for the cost problem, the biochar-graphene composite material obtained by preparing Graphene oxide (GO) and reducing it was used. Therefore, compared with Abdul's direct use of graphene composite material, the cost was much less. Therefore, it has certain guiding significance for the promotion of practical application.

\section{Conclusions}

In order to improve the adsorption effect of biochar in water treatment, BG composites are prepared by one-step dip coating. The morphology and element composition of BG composites are characterized and analyzed by SEM, TEM, XPS, and positron annihilation. The one-step dip coating method can change the surface characteristics of biochar, enable graphene to successfully adhere to the surface of biochar, form biochar-graphene composite material, and effectively improve the specific surface area and porosity of biochar. According to the results of the study, the biochar-graphene composite pyrolysis at $600{ }^{\circ} \mathrm{C}$ has the largest surface area of $251.82 \mathrm{~m}^{2} \mathrm{~g}^{-1}$. According to the analysis of dynamic adsorption, the biochar-graphene composite pyrolysis at $600^{\circ} \mathrm{C}$ can reach the adsorption balance within $48 \mathrm{~h}$, with the best adsorption effect on DMP. The adsorption balance stage is up to $35.2 \mathrm{mg} / \mathrm{g}$. The results of adsorption kinetics show that the porous structure and surface properties of BG composites regulate the adsorption rate of pollutant molecules, thus improving the adsorption performance. The results of isotherm showed that BG composites show great potential in the adsorption of phthalates.

Although BG composites with high adsorption properties were successfully prepared in this study, there are still some limitations in this study. In this research, the adsorption mechanism of biochar-graphene composites is preliminarily explored and speculated, and it is hoped that further studies can be carried out on this research.

Author Contributions: Conceptualization, D.L.; methodology, H.G.; investigation, W.W.; data curation, Z.Y.; writing-original draft preparation, Z.Y.; writing_review and editing, D.L. All authors have read and agreed to the published version of the manuscript.

Funding: This work was supported by the Fundamental Research Funds for the Central Universities (2572018BB05), and the Natural Science Foundation of Heilongjiang Province (YQ2019C004).

Acknowledgments: The authors acknowledged the help from the Northeast Forestry University.

Conflicts of Interest: The authors declare no conflict of interest. 


\section{References}

1. Abdul, G.; Zhu, X.; Chen, B. Structural characteristics of biochar-graphene nanosheet composites and their adsorption performance for phthalic acid esters. Chem. Eng. J. 2017, 319, 9-20. [CrossRef]

2. Huang, Q.; Song, S.; Chen, Z.; Hu, B.W.; Chen, J.R.; Wang, X.K. Biochar-based materials and their applications in removal of organic contaminants from wastewater: State-of-the-art review. Biochar 2019, 1, 45-73. [CrossRef]

3. Nupearachchi, C.N.; Mahatantila, K.; Vithanage, M. Application of graphene for decontamination of water; Implications for sorptive removal. Groundw. Sustain. Dev. 2017, 5, 206-215. [CrossRef]

4. Zhang, C.M.; Fu, X.L.; Zhang, X.X.; Li, J.Z. The Effects of Metal Complexes of Nano-Graphene Oxide to Thermal Decomposition of FOX-7. Nanomaterials 2020, 10, 144. [CrossRef] [PubMed]

5. Wang, J.Q.; Zhang, P.; Liang, B.; Liu, Y.X.; Xu, T.; Wang, L.F.; Cao, B.; Pan, K. Graphene oxide as an effective barrier on a porous nanofibrous membrane for water treatment. ACS Appl. Mater. Interfaces 2016, 8, 6211-6218. [CrossRef] [PubMed]

6. Xu, Z.W.; Wu, T.F.; Shi, J.; Teng, K.Y.; Wang, W.; Ma, M.J.; Li, J.; Qian, X.M.; Li, C.Y.; Fan, J.T. Photocatalytic antifouling PVDF ultrafiltration membranes based on synergy of graphene oxide and $\mathrm{TiO}_{2}$ for water treatment. J. Membr. Sci. 2016, 520, 281-293. [CrossRef]

7. Wang, H.; Mi, X.; Li, Y.; Zhan, S. 3D graphene-based macrostructures for water treatment. Adv. Mater. 2020, 32, 1806843. [CrossRef]

8. Zhao, H.; Chen, S.; Quan, X.; Hu, Y.; Zhao, H. Integration of microfiltration and visible-light-driven photocatalysis on g-C3N4 nanosheet/reduced graphene oxide membrane for enhanced water treatment. Appl. Catal. B 2016, 194, 134-140. [CrossRef]

9. Wei, Y.; Zhang, Y.; Gao, X.; Ma, Z.; Wang, X.; Gao, C. Multilayered graphene oxide membranes for water treatment: A review. Carbon 2018, 139, 964-981. [CrossRef]

10. Karkooti, A.; Yazdi, A.Z.; Chen, P.; McGregor, M.; Nazemifard, N.; Sadrzadeh, M. Development of advanced nanocomposite membranes using graphene nanoribbons and nanosheets for water treatment. J. Membr. Sci. 2018, 560, 97-107. [CrossRef]

11. Ye, S.; Liu, Y.; Feng, J. Low-density, mechanical compressible, water-induced self-recoverable graphene aerogels for water treatment. ACS Appl. Mater. Interfaces 2017, 9, 22456-22464. [CrossRef] [PubMed]

12. Mukherjee, M.; Ghorai, U.K.; Samanta, M.; Santra, A.; Das, G.; Chattopadhyay, K.K. Graphene wrapped Copper Phthalocyanine nanotube: Enhanced photocatalytic activity for industrial waste water treatment. Appl. Surf. Sci. 2017, 418, 156-162. [CrossRef]

13. Bai, T.; Lv, L.; Du, W.; Fang, W.P.; Wang, Y.S. Improving the Tribological and Anticorrosion Performance of Waterborne Polyurethane Coating by the Synergistic Effect between Modified Graphene Oxide and Polytetrafluoroethylene. Nanomaterials 2020, 10, 137. [CrossRef] [PubMed]

14. Kusiak-Nejman, E.; Morawski, A.W. TiO $2 /$ graphene-based nanocomposites for water treatment: A brief overview of charge carrier transfer, antimicrobial and photocatalytic performance. Appl. Catal. B 2019, 253, 179-186. [CrossRef]

15. Zhang, Q.; Chen, S.; Fan, X.X.; Zhang, H.G.; Quan, X. A multifunctional graphene-based nanofiltration membrane under photo-assistance for enhanced water treatment based on layer-by-layer sieving. Appl. Catal. B 2018, 224, 204-213. [CrossRef]

16. Meng, L.; Hu, Q.; Shi, C.; Huang, C. Roles of Graphene Additives in Optimizing the Microstructure and Properties of Ni-Cr-Graphene Coatings. Coatings 2020, 10, 104. [CrossRef]

17. Arshad, A.; Iqbal, J.; Siddiq, M.; Ali, M.U.; Shabbir, H.; Nazeer, B.; Saleem, M.S. Solar light triggered catalytic performance of graphene-CuO nanocomposite for waste water treatment. Ceram. Int. 2017, 43, 10654-10660. [CrossRef]

18. Huang, Y.; Ruan, G.H.; Ruan, Y.J.; Zhang, W.J.; Li, X.X.; Du, F.Y.; Hu, C.J.; Li, J.P. Hyper crosslinked porous polymers hybridized with graphene oxide for water treatment: Dye adsorption and degradation. RSC Adv. 2018, 8, 13417-13422. [CrossRef]

19. Thakur, A.K.; Singh, S.P.; Kleinberg, M.N.; Gupta, A.; Aenusch, C.J. Laser-Induced Graphene-PVA Composites as Robust Electrically Conductive Water Treatment Membranes. ACS Appl. Mater. Interfaces 2019, 11, 10914-10921. [CrossRef] 
20. Li, Y.; Zhang, R.; Tian, X.; Yang, C.; Zhou, Z. Facile synthesis of $\mathrm{Fe}_{3} \mathrm{O}_{4}$ nanoparticles decorated on 3D graphene aerogels as broad-spectrum sorbents for water treatment. Appl. Surf. Sci. 2016, 369, 11-18. [CrossRef]

21. Abd-Elhamid, A.I.; Aly, H.F.; Soliman, H.A.M.; Shanshory, A.A.E.I. Graphene oxide: Follow the oxidation mechanism and its application in water treatment. J. Mol. Liq. 2018, 265, 226-237. [CrossRef]

22. Huang, L.; Lin, H. Engineering sub-nanometer channels in two-dimensional materials for membrane gas separation. Membranes 2018, 8, 100. [CrossRef]

23. Li, X.; Sun, J.; Che, Y.; Lv, F.; Liu, F. Antibacterial properties of chitosan chloride-graphene oxide composites modified quartz sand filter media in water treatment. Int. J. Biol. Macromol. 2019, 121, 760-773. [CrossRef] [PubMed]

24. Zhu, C.; Liu, G.; Han, K.; Ye, H.; Wei, S.; Zhou, Y. One-step facile synthesis of graphene oxide/TiO ${ }_{2}$ composite as efficient photocatalytic membrane for water treatment: Crossflow filtration operation and membrane fouling analysis. Chem. Eng. Process. Process Intensif. 2017, 120, 20-26. [CrossRef]

25. Nakagawa, K.; Araya, S.; Kunimatsu, M.; Yoshioka, T.; Shintani, T.; Kamio, E. Matsuyama. Fabrication of Stacked Graphene Oxide Nanosheet Membranes Using Triethanolamine as a Crosslinker and Mild Reducing Agent for Water Treatment. Membranes 2018, 8, 130. [CrossRef]

26. Liu, G.; Han, K.; Zhou, Y.; Ye, H.Q.; Zhang, X.; Hu, J.B.; Li, X.J. Facile synthesis of highly dispersed Ag doped graphene oxide/titanate nanotubes as a visible light photocatalytic membrane for water treatment. ACS Sustain. Chem. Eng. 2018, 6, 6256-6263. [CrossRef]

27. Arshadi Rastabi, S.; Sarraf Mamoory, R.; Blomquist, N.; Phadatare, M.; Olin, H. Synthesis of a NiMoO4/3D-rgo Nanocomposite via Starch Medium Precipitation Method for Supercapacitor Performance. Batteries 2020, 6, 5. [CrossRef]

28. Lee, B.; Suh, D.W.; Hong, S.P.; Yoon, J. A surface-modified EDTA-reduced graphene oxide membrane for nanofiltration and anti-biofouling prepared by plasma post-treatment. Environ. Sci. 2019, 6, 2292-2298. [CrossRef]

29. Shakeri, A.; Salehi, H.; Nakhjiri, M.T.; Shakeri, E.; Khankeshipour, N.; Ghorbani, F. Carboxymethylcellulose -quaternary graphene oxide nanocomposite polymer hydrogel as a biodegradable draw agent for osmotic water treatment process. Cellulose 2019, 26, 1841-1853. [CrossRef]

30. Wang, Z. Efficient adsorption of dibutyl phthalate from a-queous solution by activated carbon developed from phoenix leaves. Int. J. Environ. Sci. Technol. 2015, 12, 1923-1932. [CrossRef]

31. Moazzen, M.; Khaneghah, A.M.; Sharialifar, N.; Ahmadloo, M.; ES, I.; Baghani, N.A.; Yousefinejsd, S.; Alimohammadi, M.; Azari, A.; Dobaradaran, S.; et al. Multi-walled carbon nanotubes modified with iron oxide and silver nanoparticles (MWCNT-Fe ${ }_{3} \mathrm{O}_{4} / \mathrm{Ag}$ ) as a novel adsorbent for determining PAEs in carbonaled soft drinks using magnetic SPE-GC/MS method. Arab. J. Chem. 2019, 12, 476488. [CrossRef]

32. Chen, M.; Gong, D.F. 9 Discrimination of breast tumors in ultrasonic images using an ensemble classifier based on TensorFlow framework with feature selection. J. Invest. Med. 2019, 67 (Suppl. 1), A3. 